Author-produced version of the article published in Society \& Natural

Resources, 2020, vol.33, N5, p.694-699

The original publication is available at

doi : 10.1080/08941920.2019.1673523

\title{
Magic and muck: On chicken and egg problems when framing organic conversions as transformations, and the importance of the personal sphere
}

\author{
Cyrille Rigolot \\ Inra, Université Clermont Auvergne, Vetagrosup, AgroParisTech, Irstea, UMR Territoires, Saint-Genès \\ Champanelle, France.
}

Contact: cyrille.rigolot@inrae.fr

\begin{abstract}
s
This comment aims to further develop James and Brown proposal of framing organic conversions as transformations, referring to "the three spheres of transformation" (practical, political, and personal). Particularly, I address the dynamic interactions between the three spheres during the transformational process, and challenge James and Brown's emphasis on the political sphere. To this aim, I first make explicit the temporal logic underlying James and Brown's analysis, which is consistent with other conceptualizations in literature, also giving importance to the political sphere. Then, I mention an alternative approach, highlighting the potentially initiating role of key individuals and farmers' epiphanies in the transformational process. This makes a strong difference in the narratives that can be made around organic conversions, by shedding light on the personal sphere and the "co-arising" of the three spheres. This proposal raises both methodological and theoretical questions, which can be addressed by introducing insights from quantum theory.
\end{abstract}

In their 2019 paper in Society and Natural Resources, James and Brown (2019) propose a highly relevant and timely framing of organic conversion seen as transformations. Their conceptualization refers to "the three sphere of transformation", as defined by O'Brien and Sygna (2013): (1) The practical sphere, representing behaviors and interventions; (2) The political sphere, representing "systems and structures that shape change in the practical sphere"; (3) The personal sphere, representing "the subjective dimensions that influence behaviors and interventions, and how systems and structures are perceived and experienced" (James and Brown 2019, 134, Figure 1). On the basis of a sophisticated and insightful participatory assessment, the authors propose a conceptualization inspired from resilience theory, and a discussion about interactions within, across and among political, personal and practical spheres of transformations (James and Brown 2019). Particularly, they show that there are both hard times and more enthusiastic learning experiences during organic conversion. In this comment, from my personal research experience in agricultural transformations including organic conversions, I would like to develop further the discussion opened by James and Brown (2019), putting a focus on the transformational process. Particularly, I point out that the "time sequence" of interactions raises "chicken and egg problems", because of the constant interaction and co-arising between the three spheres. This has important con- sequences on the narratives that can be made around organic conversions, notably depending on what is taken as a starting point (between 
hard times and enthusiastic learning experience; or "Muck" and "Magic", respectively, to take James and Brown's title as a metaphor). Finally, as an alternative to linear and sequential understanding of causation, I suggest that quantum approaches could be useful to conceptualize the importance of moment-to-moment interactions and the co-arising of the three spheres.

\section{Muck and Magic: James and Brown's Proposal, and Its Underlying Temporal Logic}

The first result highlighted in James and Brown's (2019) paper is the transformational nature of organic conversion, supported by evidence of shifts in understanding and management of soil fertility in the study participating farmers group. Transformations in the personal sphere are nicely illustrated by farmers' quote ("you've got to convert yourself before you convert your farm", p 139). Then, James and Brown (2019) develop the "preconditions" for decisions to convert. These preconditions are "characterized by a complex set of slow and fast changes occurring away from their farm", p 140), such as volatile global market dynamics or national animal disease events. Study participants experienced these changes "differently and unequally", but seemingly always negatively (stress, despair, fear, anxiety, reduced well-being, see Table 1 in James and Brown 2019). Moreover, "windows of opportunity [such as organic conversion subsidies] played an instrumental role in enabling participant to fortuitously escape the constrains of their conventional systems and convert their farmland to organic status" ( $p$ 141). Also, "several participants emphasize that decisions to convert were part of a complex process in which organic farming compete against other viable alternatives" ( $p$ 141). In the following result section of the paper, James and Brown (2019) highlight the role of key individuals and international agroecological shadow networks (mavericks and facilitators). Finally, the authors consider some shifts in capacity to address change beyond the farm. They high- light that these kind of shifts are rather limited, and call for increasing farmer participation opportunities in agricultural policy development.

Although James and Brown (2019) do not mention explicitly any structured trans- formational process, and rather rightfully highlight "the messy and non-linear nature of change", the structure of the paper and title of the sections ("preconditions") clearly suggest some kind of temporal logic in organic transformations (schematically: crisis, des- pair, search for alternatives, tests and networking, conversion, dissemination). This temporal logic is summed up in the paper's discussion, in link with the three spheres of transformation. The authors notably highlight the role of the political sphere especially, which "drives, enables, and constrains interplay across political, practical and personal spheres of transformation" ( $p$ 144). Generally, although James and Brown may agree with O'Brien and Sygna's (2013) in that "potential intervention points for transformation may be found within each of the spheres, but it is the interactions across the spheres where the greatest potential for generating non-linear transformation lies", it is not clear whether they also consider that "transformations in the personal sphere have more powerful consequences than in other spheres", as "paradigms can be considered the sources of systems, and beliefs and assumptions can influence the quality of connections with larger groups" (O'Brien and Sygna 2013, p 6). Rather, James and Brown (2019) mention "strikingly limited signals of transformations in the personal and practical spheres being scaled-out to effect transformations in the political sphere of agricultural production at national and international scales" ( $p$ 146).

Interestingly, the temporal logic underlying James and Brown's (2019) analysis is quite consistent with some conceptualizations of farm transformational change process in literature. For example, on the basis of inductive analyses of interviews with farmers converting to organic farming in England, Sutherland et al. (2012) propose a "triggering change cycle" in six stages: (1) Path dependency; (2) 
Trigger event; (3) Active Assessment; (4) Implementation; (5) Consolidation; (6) Return to stage 1. The overall underlying dynamic is also broadly consistent with the modeling of transformational change process proposed by Huet et al. (2018), on the basis of the literature and three seminal theoretical stream of decision-making approaches (diffusion of innovation theory, theory of planned behavior and management studies). The transformational change process described by Huet et al. (2018) is based on two phases associated with two related regimes: (1) a path dependency regime (corresponding to incremental changes only); (2) after some trigger event, a transitory regime (in which farmer search for new information and relevant networks to reduce uncertainties, whereas organic farming may compete against other viable alternatives). This process has been implemented in an agent-based model, to understand why many farmers do not convert to organic farming even when the context is seemingly favorable (Xu et al. 2018). As in James and Brown 's (2019) analysis, these studies highlight the importance of factors related to the political sphere, such as market opportunities or the necessity for farmers to comply with strict organic specifications (Xu et al. 2018).

\section{Magic and Muck: Another Possible Temporal Logic}

The analysis of Coquil, Dedieu, and Béguin (2017) share some features with the above conceptualizations (the identification of a "starting point", the importance of networks ...), but the temporal relations and emphases are different. Particularly, Coquil, Dedieu, and Béguin (2017) show that "farmers' professional transitions were initiated by four factors, and most of the time by the conjunction of at least two of the following: (i) access to the unthinkable, (ii) practical difficulties, (iii) awareness of the gap between "doing" and "thinking" and (iv) external constraint". Particularly, "access to the unthinkable refers to the subjectivity of discovery and to access to a new realm of possibilities through a discovery". Coquil, Dedieu, and Béguin (2017) illustrate this point with the specific case of a farmer who fortuitously met a pioneer of the self-sufficient and autonomous farming movement in northwestern France (a "key individual" and maverick, in James and Brown's (2019) terms). This key person suggested to the farmer to half his farm's dairy production and to feed his cows with grass, instead of using maize silage and expensive imported soybean meal. This idea was shocking at first, but then opened up new perspectives, such as the possibility to live of farming without using up his full quota entitlement (Coquil, Dedieu, and Béguin 2017). From my perspective, this example clearly illustrate the key initiating role that new ideas and farmers' epiphanies can play in the transformational process, whereas these seem to happen only "in a second time" in James and Brown's (2019) analysis.

In my opinion, insights provided by Coquil, Dedieu, and Béguin (2017) make a strong difference in the narratives that can be made around organic conversions. In James and Brown's (2019) analysis, as in other conceptualizations mentioned above (Huet et al. 2018), it seems that going through hard and painful times is an important and quite central part of the process. If we are a bit cynical and exaggerating, from a caricatured conventional point of view, this framing may suggest that farmers converting to organic have to be some kind of "losers" (at least in a first time), as they would have no reason to convert if they are currently successful and satisfied (Xu et al. 2018). Moreover, the farmer may appear a bit passive in the process, waiting that a "window of opportunity" enables him to "fortuitously escape" the constrains of his conventional system. By contrast, in highlighting the key potential initiating role of key individuals and farmers' epiphanies, Coquil, Dedieu, and Béguin (2017) give a strong importance to the personal sphere. The converting farmer appears rather as a curious and open individual, sometimes experiencing a remarkable subjective experience, with the possibility to become a "key individual" himself soon or later. Contrary to James and Brown's (2019), this analysis suggest that transformations in the personal sphere can in fact powerfully scale-out to effect 
transformations in the political sphere, through political agency in the broad sense (O'Brien 2015). Indeed, in a broad understanding, political agency recognizes that individual and collective change are in fact deeply connected (O'Brien 2015). Through social network, individuals influence more people than they think, and small individual actions can in fact have widespread global effects (O'Brien 2015). Further, in a sense, the political sphere is always a reflection of the personal sphere: Particularly, the structures that are constraining transformations to organic agriculture do not "come from nowhere". Instead, they reflect a particular view of the world (in this case of that legitimates high-input agriculture, a prioritization of yields ... ), as well as power dynamics and interests.

Finally, the present discussion raises both a methodological and a theoretical question, which are linked one to the other. From a methodological point of view, it can be argued that James and Brown's (2019) analysis correspond to the analysis of the farmers themselves, remarkably captured through the participatory resilience assessment. To some extent, the emphasis on the political sphere is a result of the discussions with the group of farmer, and not only James and Brown's interpretation. Therefore, the methodological question is why the study shows no emphasis on the initiating role of key individuals and farmers' epiphanies, as in Coquil, Dedieu, and Béguin (2017). The theoretical question concerns the possibility of free will and the potential of human agency. Indeed, an emphasis on the personal sphere suggest that individuals are able to deliberately engage in a transformational process, in spite of unfavorable constrains in the political and practical spheres. In my understanding, a promising perspective to better address both questions and the interactions between the three spheres is to introduce concepts from quantum theory, as proposed by Karen O'Brien (2016) herself. Indeed, according to O'Brien (2016), the paradigm underlying much of the current thinking is largely based on the assumption of classical physics, "where agents are discret individual or self-interested states that interact through local causation, with little or no role for subjectivity, consciousness, intentionality or free will". By contrast, a quantum ontology recognizes and legitimates the fundamental importance of subjectivity. Particularly, the International Relations scholar Alexander Wendt (2015) has recently proposed an updated version of the "quantum consciousness hypothesis", integrating the latest scientific breakthroughs in a rigorous manner. This "quantum consciousness hypothesis" could give a physical basis to explain consciousness, considered as "collapse of a quantum wave function into a defined reality, resulting in the everyday world that we perceive and experience" (O'Brien 2016). Following this approach, individuals are seen as entangled and "intra-acting", rather than fully separable entities. Moreover, social structures are seen as both external and "internal to human beings collectively" (Wendt 2015, p 208). This gives a strong meaning to the co-arising of the personal and political spheres, which can emerge through the practical sphere of transformation. As regard the methodological question, a consequence of such a quantum ontology would be that the conditions of observations fundamentally determine the outcome of the observations. In the study of Coquil, Dedieu, and Béguin (2017), the methodology used with farmers is based on elicitation interview techniques (Vermersch 2019). As shown by well-known quantum author Michel Bitbol (2014), the epistemological situation of this elicitation introspection technique is isomorphic to the epistemological situation of quantum physics, in that it fully recognize that phenomenon are not independent of the experimental situation which make them manifest. Therefore, just as James and Brown (2019) manage to show novel insights with the participatory resilience assessment, that would not be visible with classical semi-structured interviews, we can think that the elicitation technique enables additional insights to come out which are consistent with a quantum ontology, but not visible with the participatory resilience assessment.

To conclude, importantly, there is no single "right" conceptualization and narrative that can be made around organic conversions. The usefulness and relevance of a narrative will depend on its specific objectives and audience. Particularly, the reasons and motivations for farmers to engage in a process 
of conversion to organic farming are very different, depending if they are pioneers or late followers (Huet et al. 2018). In some cases, I believe that shed- ding light on the personal sphere and the enthusiastic aspects of the process might encourage some farmers to engage more proactively and positively in organic conversion, compared to a conceptualization stressing the importance of the political sphere and personal crisis. However, rather than prioritizing between agency over structure or vice versa, it seems that a key point lies in the constant interactions and co-arising between the three spheres, and the diversity of possible narratives.

\section{Funding}

This work was supported by the French Government under IDEX-ISITE Initiative 16-IDEX-0001 [CAP 2025].

\section{References}

Bitbol, M. 2014. La conscience a-t-elle une origine? Des neurosciences 'a la pleine conscience: Une nouvelle approche de l'esprit. Paris, France: Flammarion.

Coquil, X., B. Dedieu, and P. Béguin. 2017. Professional transitions towards sustainable farming systems: The development of farmers' professional worlds. Work 57(3):325-37. doi:10.3233/ WOR172565.

Huet, S., C. Rigolot, Q. Xu, Y. De Cacqueray-Valmenier, and I. Boisdon. 2018. Toward modelling of transformational change processes in farm decision-making. Agricultural Sciences 9(3): 340-50. doi:10.4236/as.2018.93024.

James, T., and K. Brown. 2019. Muck and magic: A resilience lens on organic conversions as transformation. Society and Natural Resources 32(2):133-49. doi:10.1080/08941920.2018. 1506069.

O'Brien, K., and L. Sygna. 2013. Responding to climate change: The three spheres of transformation. In Proceedings of transformation in a changing climate, 19-23 June 2013, 16-23. Oslo: University of Oslo.

O'Brien, K. 2015. Climate change. Political agency: The key to tackling climate change. Science (New York, NY) 350(6265):1170-1. doi:10.1126/science.aad0267.

O'Brien, K. 2016. Climate change and social transformations: Is it time for a quantum leap?

Wiley Interdisciplinary Reviews: Climate Change 7(5):618-26. doi:10.1002/wcc.413.

Sutherland, L. A., R. J. Burton, J. Ingram, K. Blackstock, B. Slee, and N. Gotts. 2012. Triggering change: Towards a conceptualisation of major change processes in farm decision-making. Journal of Environmental Management 104:142-51. doi: 10.1016/j.jenvman.2012.03.013.

Vermersch, P. 2019. L'entretien d'explicitation. ESF Sciences Humaines.

Wendt, A. 2015. Quantum Mind and Social Science. Cambridge, UK: Cambridge University Press.

Xu, Q., S. Huet, C. Poix, I. Boisdon, and G. Deffuant. 2018. Why do farmers not convert to organic farming? Modeling conversion to organic farming as a major change. Natural Resource Modeling 31(3):e12171. doi: 10.1111/nrm.12171. 